\title{
A Potential of a Malaysia Strain, Rhodococcus Ukmp-5m as a Biocatalyst in Bioremediation of Nitrile
}

\author{
Sjahrir F1*, Maniyam MN2, Ibrahim $\mathrm{AL}^{2}$ and Anthony EGC 3 \\ 1Faculty of Engineering and Life Sciences, Universiti Selangor, Malaysia \\ ${ }^{2}$ Institute of Bio-IT Selangor, Universiti Selangor, Malaysia \\ ${ }^{3}$ Department of Chemistry and Institute of Biomedical Engineering, Imperial College \\ London, South Kensington Campus, United Kingdom
}

\section{Review Article}

Volume 2 Issue 1

Received Date: April 01, 2017

Published Date: April 21, 2017

DOI: $10.23880 /$ oajmb-16000117

*Corresponding author: Dr Fridelina Sjahrir, Department of Science and Biotechnology, Faculty of Engineering and Life Sciences, Universiti Selangor, Jalan Timur Tambahan, 45600 Bestari Jaya, Selangor, Malaysia, Tel: +603-32805123; Email: fridelina@unisel.edu.my

\section{Abstract}

The chemical industry, such as the production of polymers, fine chemicals and pharmaceuticals, represent one of the biggest economic worldwide. This chemical industry usually produces unwanted by-products or releases the toxic or hazardous waste. To overcome these problems, numerous technologies were introduced, including biocatalysis, biotransformation, bioremediation and biodegradation which are associated with green chemistry. There are a number of microorganism involve in bioremediation of pollutants. One Malaysian isolate, Rhodococcus UKMP-5M was chosen to evaluate its potential as biocatalyst in biotransformation of nitrile. The growth of the cells was optimized and the reaction conditions in three systems were enhanced to improvise the conversion of nitrile. The application of the optimum strain in these three conditions showed promising results. It was then proven by the employment of the procedures in the real sample of nitrile-containing industrial wastewater, as a proof of concept. Therefore, it can be concluded, the purpose to establish a Malaysia isolate, Rhodococcus UKMP-5M as one of the potential industrial biocatalysts in bioremediation process has been achieved.

Keywords: Rhodococcus; Biocatalyst; Biotransformation; Nitrile

\section{Introduction}

Starting from the industrial revolution era (1900 2000), the chemical industry has become a keystone industry as practically it affects the manufacturing economy. This industry produces chemical products which are subsequently used in the manufacturing of the materials in housing, agriculture, pharmaceutical and telecommunication [1]. The global chemical market was estimated to grow from 2292 billion USD in 2008 to 3235 billion USD by 2015 and 400 billion USD by 2020 [2]. Annually, about 6 million chemical compounds inclusive of 1,000 new compounds have been synthesised and up to 95,000 chemicals are in commercial use. Thus, an enormous production of chemicals to cater the demands will take place and following of that, massive number of 


\section{Open Access Journal of Microbiology \& Biotechnology}

waste materials and pollutants will produce and dispose into the environment. According to the Third World Network reports, more than one billion pounds or 450 million kilograms of toxins are released into the air and water worldwide. The presence of the toxin in our environment causes the ecological problem and following of that lead to the imbalance nature and increase the anthropogenic effects $[3,4]$. The source of anthropogenic problems mainly from industrial leaks and spills, inappropriate uses and handling of pesticides and fire retardants, neglectful in disposal of industrial and domestic wastes, landfill, garbage dumps, oil spillage and oily waste [5].

Hence, this issue has become one of the major concerns for both industrialists and environmentalists. Therefore, a few alternative technologies have been applied in order to minimise the production of industrial wastes or to recycle them. By doing so, the industrialists believed it may lower down the cost of operation while for the environmentalists; it will keep the earth clean and safe for people to live [4]. In the early years of industrialization, the polluted areas were treated via two methods, i.e. the cap and contain method and by digging up the contaminated soil and remove it to a landfill. However, these two methods only offered interim solutions, high expenditure and other potential liabilities. Next, they moved to other conventional methods which completely destroyed the pollutants or altered them to other less harmful substances. Again, these methods also have some drawbacks such as it incurred high cost of operation as the methods employed high-temperature incineration or extreme $\mathrm{pH}$ conditions and the involvement of technological complexity. Moreover, the lack of public acceptance towards these conventional methods, also has contributed to the ineffectiveness of the methods [6].

Therefore, to overcome these problems, people are searching and exploring the alternatives and as a result, this has led to the emergence of green chemistry $[7,8]$. The term green chemistry was first introduced in 1991 by P.T. Anastas in an exclusive program launched by the United States Environmental Protection Agency (EPA) [9]. The 12 Principles of green chemistry become a guideline or reference in helping people to detoxify or remediate wastes and pollutants in safer techniques. Generally, there are three microbial processes that are related to green chemistry, i.e. biodegradation, biotransformation and biocatalysis. Each process is assigned to an individual process or these three methods can be overlapped [10]. Bioremediation which generally comprises of biodegradation and biotransformation exploits the ability of microorganisms to degrade or detoxify chemical substance or xenobiotic compounds. In this context, the role of microorganisms is to break down the toxic substance to other chemical compounds that are acceptable to the environment. These harmful chemical substance include petroleum products, aliphatic and aromatic hydrocarbon (such as polycyclic aromatic hydrocarbons, nitroaromatics and polychlorinated biphenyls), azo compounds, cyanide, organic sulfonics, industrial solvents, pesticides and their metabolite, metals and synthetic polymers $[11,12]$.

The cyano group, $(-\mathrm{C} \equiv \mathrm{N})$ can be categorised into three based on the atom or molecules bonded to it, i.e hydrogen cyanide (HCN); cyanide or also known as metal-cyano and inorganic nitrile and organonitrile. The organic nitrile (R$\mathrm{CN}$ ) are broadly used in organic chemistry as intermediates for the synthesis of numerous compounds such as amides, amines, carboxylic acids, esters, carbonyl compounds etc $[13,14]$. The nitriles $(-\mathrm{CN})$, or also known as organic cyanides, are widely found in the environment. It is also produced by plants as cyanoglycosides, cyanolipids, ricinine, phenylactonitrile etc $[8,13]$. Organonitriles group compound is generally an extremely toxic, highly carcinogenics and mutagenic [15].

Besides found in abundance in our environment, nitriles are also extensively produced in the chemical industry as it can be easily prepared by numerous chemical methods. The nitriles have been produced or used in various types of industries such as pharmaceuticals, feed stock, solvent, extractants, recrystallizing agents, catalyst and pesticides as well as an intermediate for organic synthesis for preparation of various types of amines, amides, carboxylic acids, aldehydes and ketones to name a few [16]. Nitriles are widely used in organic synthesis as precursors for compounds such as amides and organic acids. Following of this, the organonitriles are often found in the effluents of the above-mentioned industries. Hence, the treatment to detoxify organonitriles in the wastewater prior to the safe discharge is highly needed [15]. However, the chemical conversion of nitriles presents several problems such as require either strongly acidic or basic media, high energy consumption and produces the unwanted byproduct which is toxic [17].

The toxicity of nitriles is lower than that of cyanide, however the incomplete combustion of nitriles substances as well as reaction of nitriles with bases produce a highly toxic of hydrogen cyanide. In addition of that, reaction of nitriles with acids can cause a volatile reaction to occur. Besides that, a free radical oxidation of aliphatic nitriles in liver will lead to the formation of 


\section{Open Access Journal of Microbiology \& Biotechnology}

cyanohydrin and subsequently loss of hydrogen cyanide $[18,19]$. Therefore, it can be deduced that nitrile are generally highly toxic, mutagenic and carcinogenic in nature and its toxicity levels varies with their chemical structure. As in microbiology aspects, it was found having inhibitory effects of cell multiplication of some algae and sensitive bacteria such as Pseudomonas putida. Meanwhile for human, it will lead to gastric distress and vomiting, bronchial irritation, respiratory distress, convulsions and coma. The toxicity of the nitriles was reported mainly related to cyanide ion which released from the metabolism of nitriles [16].

In nature, hydrolysis of nitrile is the most common pathway for the microbial metabolism. The three different groups of enzyme involves in the hydrolysis of nitrile are nitrilase, nitrile hydratase and amidase [13]. The schematic pathway on these three enzymes is stated below:

$$
\mathrm{RCN}+\mathrm{H}_{2} \mathrm{O} \stackrel{\mathrm{RCN}+2 \mathrm{H}_{2} \mathrm{O} \stackrel{\text { NHase }}{\longrightarrow} \mathrm{R} \text {.trilase }}{\longrightarrow} \mathrm{RCONH}+\mathrm{H}_{2} \mathrm{O} \stackrel{\text { Amidase }}{\longrightarrow} \mathrm{RCOOH}+\mathrm{NH}_{3}
$$

Figure 1: The enzymatic pathway of nitrilase, nitrile hydrates (NHase) and amidase.

Microbial metabolism for removing highly toxic nitriles from industrial waste can proceeds through two different enzymatic pathways (Figure 1). Nitrile hydratase (NHase) catalyzes the hydration of a nitrile to the corresponding amide, which is then converted by amidase to the acid plus ammonia, while the second process involves direct hydrolysis of the nitrile to an acid with the release of ammonia by a nitrilase $[20,21]$. Therefore, these three enzymes were also called as nitrile-hydrolyzing enzymes with the correspondence carboxylic acid and ammonia as the final products.

\section{Biological Methods for Nitrile Biotransformation}

Biotransformation of nitrile and amide can be conducted with different types of cells, (i.e. resting cells and immobilized cells) and enzyme (i.e. free enzymes and immobilized enzymes). However, the application of native enzymes and microorganisms in green chemistry methods exhibit some weaknesses, such as its short-term stability under reaction conditions. Others are its complexity of recovery and low or non-reusability [22]. Therefore, efforts on finding a potential biocatalyst with improved activity and stability as well as reusability are actively carried out. Thus, the biotransformation method is expanded to the application of immobilized cells or enzymes. Various parameters were tested such as, type of cells (i.e growing or resting cells) and enzymes (i.e partially or fully purified enzymes) using numerous matrices (i,e hydrogel, calcium alginate, polyurethane foam, agar, cellulose triacetate gel) and techniques ( etc. adsorption of cells or enzymes on solid supports, entrapment and encapsulation, covalent attachment to solid su4pports and intermolecular crosslinking ). Immobilization of cells or enzymes provides continuous reaction for large-scale processes which in turn simplify the process control and reducing costs. Immobilized enzymes are normally employed in for the production of fine chemicals and pharmaceuticals A great matrices and techniques provide protective barriers which in turn creates longer viability for reaction and storage stability towards organic solvent, have better thermal stability and long-term stability under the reaction conditions which subsequently facilitates in the reduction of cost of production [22-25]

One of the advantages of immobilization is stabilisation of the biological agent as biocatalyst in most of the biotransformation processes. It also facilitates the reuse of an enzyme, control of cells, or support of a growing biofilm for use in a continuous system which can be performed in a bioreactor. Furthermore, the effectiveness of biotransformation systems in a bioreactor can be amplified by mathematically modelling based on the biochemical characterization, which may include modification, adaptation as well as scaling up [26]. In addition to that, bioreactor enables a continuous monitoring of systems performance as well as the control of the optimum conditions of reaction which are vital in keeping the microbial activity at the required level [27]. Parameters that can be controlled for the above mentioned purposes includes oxygen transfer, mass transfer, gas-liquid mass transfer, $\mathrm{pH}$ of the solution, concentration of substrates etc.

The type of contaminated soil may affect the effectiveness of method applied in bioremediation. For instance, a low permeability soil will subsequently hinder the incorporation of oxygen and nutrients which subsequently affect the rate of bioremediation. Hence, application in bioreactor has become a good choice of 
treatment as it provides proper mixing which in turn will increase the aeration rate and produce homogenize reaction mixture [27].

\section{Application of Rhodococcus in Nitrile Biotransformation}

There is a number of the biotransformation of organonitriles by various single isolates with the nitrilehydrolyzing enzymes of interest which is summarised in the Table 1. The biodegaration of organonitriles was also investigated using Brevibacterium imperialis CBS489-74, Candida guilliermondii CCT 7202, Kluyueromyces toleratnts MGBY 37, Klebsiella oxytoca, Nocardia rhodococcus, Rhodococcus erythropolis, Rhodococcus rhodochrous PA-34 etc. Although bioremediation of organonitrile using single isolate has created a great discovery, the application of mixed consortia is limited in the literature. Most of the bioremediation of organonitrile was conducted in aerobic conditions and only limited studies was reported on the anaerobic conditions as it showed a slow process and severely limited by the toxicity of nitriles [15].

The genus Rhodococcus was recognised as one of the most potential microorganism besides Pseudomonads for remediation of pollutants as the strains have an extensive catabolic versatility, unique enzymatic capabilities and robust cellular physiology [28,29] and which in turn, possesses the ability to degrade large number of organic compounds, ranging from natural, xenobiotic to anthropogenic compounds with high toxicity and concentrations [30,31]. The original habitat of Rhodococcus spp also contributes to the high potential microorganism applied in bioremediation. The ability to grow and endure in the diverse temperate and extreme environments such as highly polluted water and soils and oxygen- and nutrient-limited conditions without affecting the rate of degradations, has been proven [5,31] As an aerobic bacteria, the strain has the potential to degrade substance-containing oxygen and as well as reduction of nitrate [32]. Besides that, Rhodococcus is also known to produce metabolites of industrial potential such as carotenoids, biosurfactants and bioflocculant agents and acrylamide [33]. The production of biosurfactants by a number of Rhodococcus strains was observed able in the elimination of oil from polluted soils as well as enhancing the oil recovery [31].

Xenobiotic compounds, that be metabolised by Rhodococcus strains includes aliphatic and aromatic hydrocarbon, oxygenated and halogenated compounds, nitroaromatics, heterocylic compounds, nitrogenous, organo-nitrogen, nitrile and numerous pesticides. On top of that, there are various reports and observations testified the strains are able to degrade the compounds that are not readily transformed by other organisms. One of the bases on the employment of Rhodococcus in the degradation or transformation of toxic compound is its unique enzyme capabilities. A range of enzymes of Rhodococcus has been reported for this matter, i.e. phenol hydroxylase, cyanide hydratase, nitrilase and nitrile hydratase $[5,30]$.

\begin{tabular}{|c|c|c|c|}
\hline Biotransformation of & Bacteria & Enzymes & Reference \\
\hline Indole-3-acetonitrile to Indole-3-acetamide & Nocardia sp 108 & $\begin{array}{c}\text { Acrylonitrile-hydrating } \\
\text { enzymes }\end{array}$ & {$[34]$} \\
\hline $\begin{array}{c}\text { 2,2-dimethylcyclopropanecarboxamide to 2,2- } \\
\text { dimethylcyclopropanecarboxylic acid }\end{array}$ & Rhodococcus ZJUT-N595 & Amidase & {$[35]$} \\
\hline Acrylontirile to acrylamide & Mesorhozobium sp F28 & Nitrile hydratase & {$[36]$} \\
\hline Acrylonitrile - acrylamide - acrylic acids & Bacillus spp & $\begin{array}{c}\text { Nitrile hydratase and } \\
\text { amidase }\end{array}$ & {$[37]$} \\
\hline Acrylonitrile to acrylic acid & $\begin{array}{c}\text { Arthrobacter } \\
\text { mitroguajacolicus }\end{array}$ & Nitrilase & {$[38]$} \\
\cline { 2 - 4 } & Streptomyces sp. & Nitrilase & {$[39]$} \\
\hline Nicotinamide to nicotinic acid & $\begin{array}{c}\text { Microbacterium imperialis } \\
\text { CBS 498-74 }\end{array}$ & Amidase & {$[40]$} \\
\hline 4-cyanopyridine to isonicotinic acid & Nocardia globerula NHB-2 & Nitrilase & {$[41]$} \\
\hline 3-cyanopyridine to nicotinic acid & Bacillus pallidus Dac521 & Nitrilase & {$[42]$} \\
\hline Glycolonitrile to glycolic acid & Alcaligenes sp. ECU0401 & Nitrilase & {$[21]$} \\
\hline
\end{tabular}

Table 1: Examples of biotransformation of organonitrile by nitrile-hydrolyzing enzymes of interest of a single isolate. 


\section{Open Access Journal of Microbiology \& Biotechnology}

\section{Biotransformation of Nitrile by Rhododoccus Ukmp-5m}

The present study was taken in context to assess the suitability of the Malaysia isolate, Rhodococcus UKMP-5M as a source of biocatalyst in biotransformation of nitrile, which is found in abundance as industrials wastes from polymer-based industries. Rhodococcus UKMP-5M has proven its capability to remediate phenol, cyanide, polychlorinated compounds as well as a biocatalyst in the production of biodiesel by members of the research group. Rhodococcus UKMP-5M was isolated from petroleum contaminated compound in Melaka, Malaysia and kept in Unisel Culture Collection. The gene discovery result of the strain showed it has 21 gene classes which consist of halogenases, alkane catabolism, nitrile catabolism and phenol catabolism.

The first phase of work was to find the optimum culture condition for both the growth and the nitrilehydrolyzing enzymes activity. The optimization studies were conducted using OVAT (one-variable-at-a-time) techniques. The selection of the significant optimum parameter was chosen using one-way ANOVA of SPSS. In the present work, two optimum culture conditions have been recorded (Table 2). First is a non-alteration $\mathrm{pH}$ of minimal medium supplemented with $4 \% \mathrm{v} / \mathrm{v}$ of propionitrile $\left(\mathrm{CH}_{3} \mathrm{CH}_{2} \mathrm{CN}\right)$ as inducer and $2 \% \mathrm{v} / \mathrm{v}$ of inoculum size; with 24 hours incubation at the temperature of $30^{\circ} \mathrm{C}$ while in the second optimum culture conditions, a $2 \% \mathrm{v} / \mathrm{v}$ of inoculum added in a $\mathrm{pH} 8$ of carbon and nitrogen rich medium supplemented with $4 \%$ $\mathrm{v} / \mathrm{v}$ of propionitrile and incubated at $35^{\circ} \mathrm{C}$ for 48 hours was recorded. A five-fold higher nitrile-hydrolyzing enzymes activity was detected in the first set of optimum culture conditions $\left(3.8651 \pm 0.4671\right.$ nmoles $\mathrm{mL}^{-1} \mathrm{~min}^{-1}$ $\mathrm{mg}^{-1}$ dry cell weight) as compared to the second set (0.6195 $\pm 0.0244 \mathrm{nmoles}_{\mathrm{mL}}^{-1} \mathrm{~min}^{-1} \mathrm{mg}^{-1}$ dry cell weight). Therefore, the first set of optimum culture conditions was used for further work. Addition of glucose in the system with propionitrile as the inducer, at the initial stage of experiment was observed only facilitated the growth of the cells.

\begin{tabular}{|c|c|c|}
\hline & Set 1 & Set 2 \\
\hline Medium & Minimal Medium & Rich medium \\
\hline Temperature of Incubation & $30 \stackrel{\circ}{C}$ & $35^{\circ} \mathrm{C}$ \\
\hline Time of Incubation & 24 hours & 48 hours \\
\hline Size of Inoculum & $2 \% \mathrm{v} / \mathrm{v}$ & $2 \% \mathrm{v} / \mathrm{v}$ \\
\hline Types of Inducer & Propionitrile $\left(\mathrm{CH}_{3} \mathrm{CHCN}\right)$ & Propionitrile $\left(\mathrm{CH}_{3} \mathrm{CHCN}\right)$ \\
\hline Percentage of the best inducer & $4 \% \mathrm{v} / \mathrm{v}$ & $4 \% \mathrm{v} / \mathrm{v}$ \\
\hline Initial $\mathrm{pH}$ of medium & Non-alteration $\mathrm{pH}$ medium & 8 \\
\hline $\begin{array}{l}\text { Nitrile-hydrolyzing enyzmes activity at } \\
\text { optimum culture conditions }\end{array}$ & $\begin{array}{c}3.8651 \pm 0.4671 \mathrm{nmoles} \mathrm{mL}^{-1} \mathrm{~min}^{-1} \\
\mathrm{mg}^{-1} \text { dry cell weight }\end{array}$ & 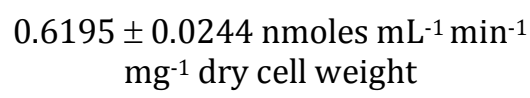 \\
\hline
\end{tabular}

Table 2: Two sets of optimum culture conditions of Rhodococcus UKMP-5M.

The resting cells from the optimally grown cells of Rhodococcus UKMP-5M were employed to find the reaction conditions that favour the conversion of acrylonitrile to ammonia, the most. A wide range of parameters were varied and the outcomes were two hours of reaction at a temperature of $30^{\circ} \mathrm{C}$, agitation of 80 $\mathrm{rpm}$, initial pH of phosphate buffer of 6 and $5 \% \mathrm{v} / \mathrm{v}$ of size of inoculum with nitrile-hydrolyzing enzymes activity of $0.1518 \pm 0.0458 \mu$ moles $\mathrm{mL}^{-1} \mathrm{~min}^{-1}$ was recorded. The optimum resting cells of Rhodococcus UKMP-5M was observed having a potential as a biocatalyst as it can tolerate higher concentration of substrate up to $150 \mathrm{mM}$ and has good thermal stability. In addition to that, the strain demonstrated high affinity towards heterocyclic and aromatic nitriles and amides as well as longer chain of aliphatic nitriles and amides. Similar findings were also observed by other researchers $[43,44]$

The biotransformation of acrylonitrile was also conducted using immobilized cells of Rhodococcus UKMP5M. Various parameters were tested, such as types of cells (growing and resting), types of matrices, cell loading and immobilization methods. From the observation, the biotransformation using immobilized cells can performed best using immobilized of growing cells in polyurethane foam cube at as size of $1 \mathrm{~cm} \times 1 \mathrm{~cm} \times 1 \mathrm{~cm}$ using entrapment techniques and a moderate cell loading. The optimized immobilized cells of Rhodococcus UKMP-5M demonstrated higher tolerance of concentration of substrate, up to $200 \mathrm{mM}$, with comparison of resting cells 


\section{Open Access Journal of Microbiology \& Biotechnology}

and it can be recycled up to 46 times with $56 \%$ of the initial nitrile-hydrolyzing enzymes activity.

Nitrile-hydrolyzing enzymes were generally unstable for commercial use in the isolated or purified state. Thus, most of the applications of the enzymes as biocatalyst is conducted as whole (or resting) cells or immobilized cells [45]. However, there are a few drawbacks reported in the application of whole cell biocatalyst, i.e. the utilisation of simple aliphatic nitrile by the biocatalyst and low concentrations of product detected $[45,46]$. In addition, there is a review report stated that the activity of isolated enzymes can be accomplished in a shorter period of time as compared to resting cells [47]. However, this type of cells is not preferable as the cell wall of Rhodococcus sp. is difficult to disrupt. The initial work of the application of intracellular nitrile-hydrolyzing enzymes was the determination of the best of the simple cell disruption methods (such as glass beads, mortar and pestle and homogenizer) and the mortar and pestle using liquid nitrogen was turned out to be the optimal. The cell free extract was detected able to convert the substrate at a shorter time of reaction as compared to resting cells which were 15 and 120 minutes, respectively with the almost equal value of nitrile-hydrolyzing enzymes activity. Besides that, it is proven that a good storage system of cell lysate at the temperature of $-80^{\circ} \mathrm{C}$ has significantly maintained the enzyme activity.

Early works demonstrated that both pathways of nitrilase and nitrile hydratase/amidase could occur in the same strains and those enzymes involved were produced selectively by the addition of different inducers [48]. Therefore, cell lysate of Rhodococcus UKMP-5M from a few systems in this projects (uninduced, induced with propionitrile and acryolonitrile and reacted with both of the susbtrate) were applied in the SDS-PAGE experiment to observe the band of protein that being up regulated in the reaction. It was discovered that the responsible nitrile-hydrolyzing enzymes involved was nitrilase. The uninduced system exhibited insignificant amount of each enzymes; nitrilase, nitrile hydratase and amidase. The intracellular nitrile-hydrolyzing enzymes revealed better kinetic profile as compared to resting cells, i.e. calculated $\mathrm{K}_{\mathrm{m}}$ of 125.34 and $18.11 \mu \mathrm{M} /$ Min and calculated $\mathrm{V}_{\max }$ of 127.52 and $32.17 \mathrm{mM}$, respectively.

The climax of the work was the application of three optimum conditions produced in this work in the real untreated industrial wastewater, which was obtained from a prominent international manufacturer of nitrile gloves. The preliminary analysis of the industrial wastewater showed that the sample is complex mixture with low level of biodegradability. The sample has BOD/COD ratio of 0.08 , high number of oil and grease as well as high NTU (nephelometric turbidity unit) values which conclude that the sample is difficult to remediate using microorganisms $[49,50]$. The cells were tested to grow in the sample and as predicted, the growth of the cells with $2 \% \mathrm{v} / \mathrm{v}$ of inoculum size has prolonged with a longer time need during the lag phase. The 10 and $20 \%$ $\mathrm{v} / \mathrm{v}$ demonstrated growth after five days of incubation. The usage of the sample as inducer for the cells to grow, showed promising result. However, low nitrile-hyrolyzing enzymes activity was detected. The nitrile-hydrolyzing enzymes activity using optimum resting and immobolized cells in the industrial wastewater sample showed similar results, i.e. the immobilized cells can tolerate higher concentration of sample (10\% dilution) as compared to resting cells ( $25 \%$ dilution) with almost equal value of activity. The cell lysate from the industrial wastewater system also displayed nitrilase as the dominant enzymes. The outcome of the study showed a good potential of application of Rhodococcus UKMP-5M as biocatalyst in the bioremediation of industrial wastewater.

\section{Conclusion}

The present study has produces two significant findings, i.e. a new knowledge and new protocol or technique. New knowledge in growing Rhodococcus UKMP-5M to produce nitrile-hydrolyzing enzymes, in two different sets of culture conditions, gives good contributions to the research team for further studies, such as exploiting the capability of Rhodococcus UKMP$5 \mathrm{M}$ as well as nitrile-hydrolyzing enzymes, in the development of product from biotransformation. In addition to that, it was observed that the activity of crude nitrile-hydrolyzing enzymes has not declined after a certain period of time of storage at the temperature of $80^{\circ} \mathrm{C}$. Apart from that, a new technology was also established from the studies. i.e simple procedures in immobilizing Rhodococcus UKMP-5M in a low cost and durable matrices, which can be used repeatedly as well as tolerable to higher concentrations of substrate. These two findings give good opportunities to the research team to do proof of concept studies, i.e the employment of the strain in the industrial wastewater sample. A preliminary investigation revealed that the strain has the capability as biocatalyst in the bioremediation of real industrial wastewater containing nitrile.

Collectively, Rhodococcus UKMP-5M was proven having a good potential to act as a biocatalyst in a biotransformation of nitrile as well as in the industrial 
wastewater. In order to maximise the role, the strain can be applied as free resting cells or immobilized cells based on the purpose of the reaction. In addition, with the abundance of nitrile in industrial wastes, the ability of Rhodococcus UKMP-5M as a source of biocatalyst for the remediation of the substance can be amplified by enhancement of the reaction or other parameters pertaining to it. Following this, it can be suggested that Rhodococcus UKMP-5M as one of the potential sources of industrial biocatalyst. Furthermore, the outcomes of this project serve as an option in treating the wastes as well as greening the country and consequently lead to the generation of wealth creation. It can be achieved with the addition of Rhodococcus UKMP-5M in the existing library of Malaysia isolate as a potential natural biodegrader and biocatalyst.

\section{References}

1. Ghisalba O, Meyer H, Wohlgemuth R (2010) Industrial biotransformation. In: MC Flickinger (ed.), Encyclopedia of Industrial Biotechnology, Bioprocess, Bioseparation and Cell Technology. John Wiley \& Sons Inc, New Jersey, USA.

2. Thomas SM, DiCosimo R, Nagarajan V (2002) Biocatalysis: A applications \& potentials for the chemical industry. Trends in Biotechnology 20(6): 238-242.

3. Sharma S (2012) Bioremediation: Features, strategies \& application. Asian Journal of Pharmacy and Life Science 2(2): 202-213.

4. Shukla KP, Singh NK, Sharma S (2010) Bioremediation, Development, current practices \& perspectives. Genetics Engineering and Biotechnology Journal 3: 1-20.

5. Kuyukina MS, Ivshina IB (2010) Application of Rhododoccus in bioremediation of contaminated environements. In: HM Alvarez (ed.), Biology of Rhodococcus, Springer-Verlag.

6. Vidali M (2001) Bioremediation- An Overview. Pure and Applied Chemistry 73(7): 1163-1172.

7. Clark JH (2009) Chemistry goes green. Nature Chemistry 1: 12-13.

8. Gong JS, Lu ZM, Li H, Shi JS, Zhou ZM, et al. (2012) Nitrilases in nitrile biocatalysis, recent progress and forthcoming research. Microbial Cell Factories 11: 142-159.
9. Wardencki W, Curylo J, Namieśnik J (2005) Green Chemistry -Current \& future issue. Pol J Environ Stud 14(4): 389-395.

10. Parales RE, Bruce NN, Schmid A, Wackett LP (2002) Biodegradation, Biotransformation \& Biocatalyst (B3). Applied Environmental Microbiology 68(10): 4699-4709.

11. Jain RK, Kapur M, Labana S, Lal B, Sarma PM, et al. (2005) Microbial diversity, Application of microorganisms for the biodegradation of xenobiotics. Current Science 89: 101-112.

12. Fetzner S (2002) Biodegradation of xenobiotics. In: Doelle and da Silva (eds.), Enclyclopedia of Life Support Systems (EOLLS) Biotechnology Vol X, Eolls Publisher, Oxford, United Kingdom.

13. Banerjee A, Sharma R, Banerjee UC (2002) The nitrile-degrading enzymes, current status and future prospects. Appl Microbiol Biotechnol 60(1-2): 33-44.

14. Wang MX (2015) Enantioselective biotransformation of nitriles in organic synthesis. Acc Chem Res 48(3): 602-611.

15. Li T, Liu J, Ban R, Ohandja DG, Wong FS (2007) Biodegradation of organonitriles by adapted activated sludge consortium with acetonitriledegrading microorganism. Water Research 41(15): 3465-3473.

16. Ramakrishna C, Dave H, Ravindranathan M (1999) Microbial metabolism of nitriles and its biotechnological potential. Journal of Scientific and Industrial Research 58(12): 925-947.

17. Nagasawa, T, Yamada H (1995) Microbial Production of Commodity Chemicals - Technical Report. Pure and Applied Chemistry 67(7): 1241-1256.

18. Batthacharya R, Satpute RM, Harikarakrishnan J, Tripathi T, Saxena PB (2009) Acute technology of some synthetic cyanogens in rats and their response to oral treatment with alpha-ketoglutarate. Food and Chemical Toxicology 47(9): 2314-2320.

19. Johansen FR, Levinkas GJ (1986) Relationship between toxicity and structure of aliphatic nitriles. Fundamental and Applied Toxicology 7(4): 690-697.

20. Kobayashi M, Shimizu S (2000) Nitrile hydrolases. Current Opinion in Chemical Biology 4(1): 95-102. 


\section{Open Access Journal of Microbiology \& Biotechnology}

21. He YC, Hu JH, Su JH, Zhou L (2010) Bioproduction of glycolic acid from glycolonitrile with a new bacterial isolate of Alcaligenes sp. ECU 0401. Applied Biochemistry and Biotechnology 160(5): 1428-1440.

22. Xie T, Wang A, Huang L, Li H, Chen Z, et al. (2009) Recent advance in the support \& technology used in enzyme immobilisation. African Journal of Biotechnology 8(19): 4724-4733.

23. Hawkings $S$ (2006) Industrial Catalysis, A Practical Approach. John Wiley \& Sons. New Jersey, USA

24. Górecka E, Jastrzębska M (2011) Immobilization techniques and biopolymer carriers. Biotechnology and Food Science 75(1): 65-86.

25. Sheldon R, Arends I, Hanefeld U (2007) Green Chemistry \& Catalysis. Wiley-VCH, Weinheim, Grermany

26. Burton SG (2001) Development of bioreactors for application of biocatalysts in biotransformation and bioremediation. Pure Appl Chem 73(1): 77-83.

27. de La Rizzo AC, dos Santos RM, dos Santos RLC, Soriano AU, da Cunha CD, et al. (2010) Petroleumcontaminated soil in a new solid phase bioreactor. Journal of Chemical Technology and Biotechnology 85(9): 1260-1267.

28. van der Geize R, Dijkhuizen L (2004) Harnessing the catabolic diversity of rhodococci for environmental and biotechnological application. Curr Opin Microbiol 7(3): 255-261.

29. Larkin M J, Kulakov LA, Allen CCR (2005) Biodegradation and Rhodococcus - Masters of catabolic versatility. Curr Opin Biotechnol 16(3): 282290.

30. Foster A, Barnes N, Speight R, Keave M (2014) The repertoire of nitrogen assimilation in Rhodococcus, Catalysis, pathways and relevance in biotechnology and bioremediation. Journal of Chemical Technology and Biotechnology 89(6): 787-802.

31. de Carvalho CCR, Costa SS, Fernandes P, Cauto I, Viveiras M (2014) Membrane transport systems and the biodegradation potential and pathogenicity of genus Rhodococcus. Frontiers in Physiology 5: 133141.
32. Larkin MJ, Kulakov LA, Allen CCR (2010) Rhodococcus. In: KN Timmis (ed.), Handbook of Hydrocarbon \& Lipid Microbiology. Springer-Verlag, Berlin Heidelberg.

33. Gürtler V, Seviour RJ (2010) Systematics of Members of the genus Rhodococcus (Zopf 1981) Emend Goodfellow et al. 1998 - The past, present \& future. In H.M. Alvarez (ed.), Biology of Rhodococcus Microbiology Monographs 16, Springer-Verlag, Berlin Neidelberg,

34. Wang YJ, Zheng YG, Xue JP, Shen, YC (2006) Microbial transformation of indole-3-acetonitrile to indole-3acetamide by Nocardia sp. 108. Process Biochemistry 41(8): 1746-1750.

35. Hu JG, Wang YJ, Zheng YG, Shen YC (2007) Isolation of glycolonitrile-hydrolyzing microorganism based on colorimetric reaction. Enzyme \& Microbial Technology 41(3): 244-249.

36. Feng YS, Chen PC, Wen FS, Hsiao WY, Lee CM (2008) Nitrile hydratase from Mesorhizobium sp. F28 and its potential for nitrile biotransformation. Process Biochemistry 43(12): 1391-1397.

37. Graham D, Pereira R, Barfield D, Cowan (2000) Nitrile biotransformation using free and immobilised cells of a thermophilic Bacillus spp. Enzyme and Microbial Technology 26(5-6): 368-373.

38. Shen M, Zheng YG, Shen YC (2009) Isolation and characterization of a novel Arthrobacter nitroguajacolicus ZJUTB06-99, capable of converting acrylonitrile to acrylic acid. Process Biochemistry 44: 781-785.

39. Nigam VK, Khandelwal AK, Gothwal RK, Mohan MK, Choudhury B, et al. (2009) Nitrilase-catalysed conversion of acrylonitrile by free \& immobilised cells of Streptomyces sp. Journal of Bioscience 34(1): 2126.

40. Cantarella M, Cantarella L, Gallifuoco A, Intellini R, Kaplan O, et al. (2008) Amidase-catalyzed production of nicotinic acid in batch and continuous stirred membrane reactors. Enzyme and Microbial Technology 42: 222-229.

41. Sharma NN, Sharma M, Bhalla TC (2012) Nocardia globerula NHB-2 nitrilase catalysed biotransformation of 4-cyanopyridine to isonicotinic acid. AMB Express 2(1): 25. 
42. Almatawah QA, Cowan DA (1999) Thermostable nitrilase catalysed production of nicotinic acid from 3-cyanopyridine. Enzyme and Microbial Technology 25(8-9): 718-724.

43. Babu V, Shilpi A, Choudhury B (2010) Nitrilemetabolizing potential of Amycolatopsis sp. IITR215. Process Biochemistry 45: 866-873.

44. O'Reilly C, Turner PD (2003) The nitrilase family of $\mathrm{CN}$ hydrolysing enzymes- a comparative study. J Appl Microbiol 95(6): 1161-1174.

45. Frederick J (2006) Characterisation of nitrile biocatalytic activity of Rhodococcusrhodochrous. MSc Thesis, University of Witwatersrand, Johannesberg.

46. Meth-Cohn O, Wang CM (1997) An in-depth study of the biotransformation of nitrile into amide and/or acid using Rhodococcusrhodochrous AJ2701. Journal of Chemical Society Perkin-Trans 1: 1099-1104.
47. Faber K (1997) Biotransformation of non-natural compounds - State of the art and future development. Pure and Applied Chemistry 69(8): 1613-1632.

48. Chen J, Zheng YG, Shen YC (2008) Biotransformation of $\rho$-methozyphenylacetonitrile into $\rho$ methoxyphenylacetic acid by resting cells of Bacillus subtilis. Biotechnology and Applied Biochemistry 50(3): 147-153.

49. Manahan SE (2000) Environmental Chemistry $7^{\text {th }}$ (Edn.) CRC Press LLC, Florida USA.

50. Jie Z, Ming N, Xianqiang R, Binjie X, Xianghu L, et al. (2011) Treatment of acrylonitrile production effluent by an advanced oxidation process. Research Journal of Chemistry and Environment 15(1): 92-96.

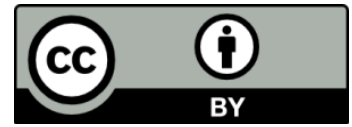

